\title{
Incretin mimetics: a novel therapeutic option for patients with type 2 diabetes - a review
}

This article was published in the following Dove Press journal:

Diabetes, Metabolic Syndrome and Obesity:Targets and Therapy

14 May 2010

Number of times this article has been viewed

\author{
Katrine B Hansen' \\ Tina Vilsbøll ${ }^{2}$ \\ Filip K Knop ${ }^{2}$ \\ 'Department of Clinical Physiology, \\ Glostrup Hospital, University of \\ Copenhagen, Denmark; ${ }^{2}$ Diabetes \\ Research Division, Department of \\ Internal Medicine F, Gentofte Hospital, \\ University of Copenhagen, Denmark
}

Correspondence: Katrine B Hansen Department of Clinical Physiology, Glostrup Hospital, University of Copenhagen, Nordre Ringvej 57, DK-2600 Glostrup, Denmark

Tel +4540509942

Fax +4543233928

Email kbaggehansen@dadlnet.dk

\begin{abstract}
Type 2 diabetes mellitus is a metabolic disease associated with low quality of life and early death. The goal in diabetes treatment is to prevent these outcomes by tight glycemic control and minimizing vascular risk factors. So far, even intensified combination regimen with the traditional antidiabetes agents have failed to obtain these goals. Incretin mimetics are a new class of antidiabetes drugs which involve modulation of the incretin system. They bind to and activate glucagon-like peptide-1 (GLP-1) receptors on pancreatic beta-cells following which insulin secretion and synthesis are initiated. Since the compounds have no insulinotropic activity at lower glucose concentrations the risk of hypoglycemia - a well-known shortcoming of existing antidiabetes treatments - is low. Additionally, incretin mimetics have been shown to be associated with beneficial effects on cardiovascular risk factors such as weight loss, decrease in blood pressure and changes in lipid profile. Current clinical data on the two available incretin mimetics, exenatide and liraglutide, are evaluated in this review, focusing on pharmacology, efficacy, safety and tolerability. The review is built on a systematic PubMed and Medline search for publications with the key words GLP-1 receptor agonist, exenatide, liraglutide and type 2 diabetes mellitus up to January 2009.
\end{abstract}

Keywords: glucagon-like peptide-1 (GLP-1), exenatide, liraglutide, type 2 diabetes

\section{Introduction}

Type 2 diabetes is a metabolic disease characterized by high blood glucose caused by an insufficiency of the pancreas to produce insulin, hyperglucagonemia and impaired insulin sensitivity. The typical symptoms include thirst, polyuria, recurrent infections and weight loss. ${ }^{1}$ However, the majority of patients do not experience symptoms and are diagnosed in a late stage of the disease. The etiology of type 2 diabetes is unknown; however, genetic and environmental factors have been linked to its development. It is a chronic progressive disease associated with micro- and macrovascular complications such as nephropathy, neuropathy, retinopathy and cardiovascular morbidity. These complications often result in low quality of life and early death. In 2000 the global mortality due to diabetes was estimated to be $5.2 \%$ or 2.9 million deaths. ${ }^{2}$ The increased mortality is mainly due to cardiovascular events. Recent estimates indicate that 171 million people worldwide had diabetes in 2000 and this number is projected to increase to 366 million by $2030 .{ }^{3}$ As a consequence, diabetes-related deaths are likely to increase by more than $50 \%$ in the next 10 years. In developed countries most people with diabetes are above 64 years of age while most people with diabetes in the developing countries are younger (45 to 64 years). ${ }^{4}$ The disease is equally distributed among sexes. ${ }^{3}$ 
The goal with diabetes treatment is to improve quality of life and prevent early death. It is well established that tight glycemic control reduces the risk of microvascular disease ${ }^{5-7}$ while recent randomized controlled trials have failed to show a substantial benefit on macrovascular outcomes. ${ }^{7-9}$ These results implicate that not only glycemic control but also minimizing cardiovascular risk factors (high blood pressure, hyperlipidemia, overweight, smoking, thrombosis risk) through medical intervention and life-style intervention should be addressed in the treatment of diabetes.

The optimal goal for glycemic control is a glycosylated hemoglobin $\mathrm{A}_{1 \mathrm{c}}\left(\mathrm{HbA}_{1 \mathrm{c}}\right)$ below $7 \% .^{10}$ In order to reach this target an intensified regimen with combinations of antidiabetes agents is often needed. Oral agents in monotherapy (thiazolidinediones [TZDs], metformin, repaglinide, $\alpha$-glucosidase inhibitors and sulfonylurea [SU] compounds) improve glycemic control to almost the same degree (decrease in $\mathrm{HbA}_{1 \mathrm{c}}$ of approximately $1 \%$ ). ${ }^{11}$ When combining two antidiabetes drugs another $1 \% \mathrm{HbA}_{1 \mathrm{c}}$ reduction can be obtained. However, with time, supplementation with subcutaneous (sc) injections of insulin or insulin analogues is often necessary in order to compensate for insulin deficiency and maintain an acceptable glycemic control. This is partly due to the fact that type 2 diabetes is a progressive disease with an almost linear decline in beta-cell function (probably combined with a decrease in beta-cell mass) over time. None of the mentioned antidiabetes drugs have been shown to preserve pancreatic beta-cell function over time and, notably, SUs have been shown to accelerate the apoptosis of human beta-cells. ${ }^{12}$ Besides, the current available drugs are associated with a number of shortcomings: body weight increase (TZDs, SUs and insulin), hypoglycemia (SUs, repaglinides and insulin) and gastrointestinal side effects (metformin and $\alpha$-glucosidase inhibitors). ${ }^{11}$ The limitations of the pre-existing antidiabetes treatments, make new medical therapies that offer improved efficacy and/or durability, better convenience, and an improved safety and tolerability profile an absolutely imperative in order to get more patients to glycemic goal initially and to avoid or delay the need for additional treatment.

\section{Incretin hormones}

The incretin hormones glucagon-like peptide-1 (GLP-1) and glucose-dependent insulinotropic polypeptide (GIP) are intestinal peptide hormones released in response to ingestion of meals. ${ }^{13}$ The most important effect of GLP-1 and GIP is their ability to potentiate glucose-induced insulin secretion from the pancreas - the so-called incretin effect. In healthy subjects the incretin effect accounts for up to $70 \%$ of the insulin secreted in response to glucose ingestion. ${ }^{14}$ GLP-1 is a 30 -amino acid polypeptide processed from proglucagon in the endocrine L-cells distributed primarily in the mucosa of the distal part of the small intestine and colon. GIP is a 42-amino acid polypeptide released from endocrine K-cells found in the mucosa of the duodenum and upper jejunum. ${ }^{15}$ While GLP-1 is rapidly degraded (by the ubiquitous enzyme dipeptidyl peptidase-4 (DPP-4)) in the circulation with an apparent half-life of 1 to 1.5 minutes ${ }^{16}$ GIP is degraded more slowly, with a half-life for the intact hormone of 7 minutes. ${ }^{17}$ The hormones enhance insulin secretion from the beginning of a meal, but has no insulinotropic activity at lower glucose concentrations (less than $4 \mathrm{mM}$ ); thereby not promoting hypoglycemia. GLP-1 also enhances insulin biosynthesis and insulin gene expression. In addition, it exerts trophic and protective actions on the beta-cells ${ }^{18}$ and strongly inhibits pancreatic glucagon secretion in a glucose-dependent manner. ${ }^{19}$ In contrast, GIP has been shown to stimulate glucagon secretion. The hormones exhibit their insulinotropic effect via G-protein coupled receptors on the pancreatic beta-cells. ${ }^{20}$ Beside the effects on the endocrine pancreas, both hormones have several other functions. GLP-1 receptors are found in various regions of the brain ${ }^{21}$ and when activated these are believed to promote feeling of satiety which in combination with GLP-1-induced inhibition of gastrointestinal motility (mediated through the vagus nerve ${ }^{22}$ ) reduces food intake and body weight. GLP-1 receptors are also found in the hear ${ }^{23}$ and most data suggest that GLP-1 exerts protective effects on the myocardium. GLP-1 has also been found to reduce the postprandial rise in triglycerides and lower the concentration of free fatty acids in humans. ${ }^{24}$ Finally, animal as well as human studies indicate that GLP-1 has natriuretic and diuretic properties by modulation of renal $\mathrm{Na}^{+} / \mathrm{H}^{+}$exchange ${ }^{25}-$ a mechanism that might serve to reduce blood pressure. GIP appears to have no physiological effect on the gastrointestinal tract, appetite or food intake, but may play a role in $\mathrm{lipid}^{26}$ and bone metabolism. ${ }^{27}$

\section{Incretin hormones and type 2 diabetes pathophysiology}

In patients with type 2 diabetes the incretin effect is severely reduced. ${ }^{28,29}$ This pathophysiological trait is likely to play a central role in the inability of these patients to secrete sufficient amount of insulin to prevent hyperglycemia following oral glucose. ${ }^{30}$ Attenuated postprandial secretion ${ }^{31}$ and decreased insulinotropic potency of GLP- $1^{32}$ in combination with abolished insulinotropic effect of $\mathrm{GIP}^{33}$ seem to be responsible for the reduced incretin effect in patients with type 2 diabetes. Since the insulinotropic effect of only GLP-1 (and not GIP) is 
preserved in patients with type 2 diabetes, antidiabetes treatment modalities based on the effect of this peptide have been developed. Interestingly, intravenous (iv) infusion of native GLP-1 is capable of normalizing blood glucose in patients with type 2 diabetes, ${ }^{34}$ but due to the short half-life of GLP-1, therapeutic administration of native GLP-1 is impractical. Therefore, in order to exploit the beneficial actions of GLP-1 in type 2 diabetes, long-acting stable receptor agonists of GLP-1 (incretin mimetics) have been developed. In the following section the current clinical data on the two available incretin mimetics, exenatide and liraglutide, will be described.

\section{Incretin mimetics}

Exenatide, the first in this new class of drugs, was introduced to the market in the United States in 2005 and in Europe in 2007 under the trade name Byetta ${ }^{\circledR}$ (Amylin Pharmaceuticals/Eli Lilly). Liraglutide has been introduced to the market in Europe July 2009 and in the United States and Japan in January 2010 under the trade name Victoza ${ }^{\circledR}$ (Novo Nordisk). The current review focuses on only these two incretin mimetics.

\section{Pharmacology}

\section{Exenatide}

Exenatide was isolated from the saliva of the lizard Heloderma suspectum in a search for biologically active peptides. ${ }^{35}$ Exenatide shares 53\% homology with native GLP-1 (Figure 1) and binds to and activates GLP-1 receptors on pancreatic beta-cells following which insulin secretion and synthesis is initiated. ${ }^{36}$ Following sc administration, exenatide is rapidly absorbed reaching peak concentrations in approximately 2 hours. The half-life of exenatide is approximately 2 hours, and after sc injection of the maximally tolerated dose, significant elevation of exenatide in plasma may be observed for 5 to 6 hours. Exposure is negligible after 12 hours post dose, explaining why twice-daily dosing is needed in order to obtain full effect on glycemic control. ${ }^{37}$ Exenatide is, unlike native GLP-1, not substantially degraded by DPP-4 but is cleared primarily in the kidneys by glomerular filtration ${ }^{38}$ resulting in a plasma half-life for the peptide of approximately $30 \mathrm{~min}$ utes after iv administration. ${ }^{37}$ Pharmacokinetics, safety and efficacy of exenatide have been tested in several subgroups of type 2 diabetes patients. In a rather small study of adolescent patients with type 2 diabetes, administration of exenatide appeared to be well tolerated, ${ }^{39}$ in a study of Japanese patients with type 2 diabetes the pharmacokinetics seemed to be similar to that of Caucasian patients ${ }^{40}$ (no racial differences have been reported). Lastly, age does not seem to influence the pharmacokinetic properties of exenatide. ${ }^{41}$

\section{Liraglutide}

Liraglutide is an acylated analogue of human GLP-1 and has 97\% sequence homology to native GLP-1 (Figure 1). The

\section{A}

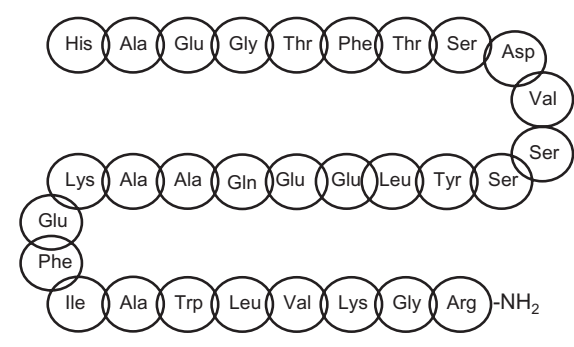

C

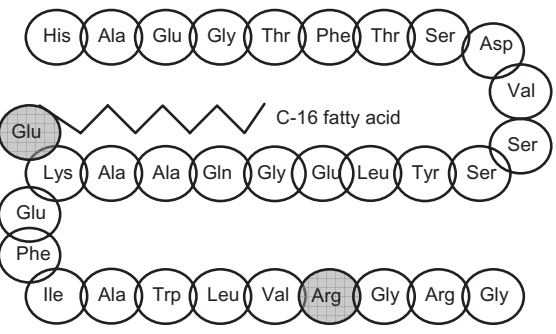

B

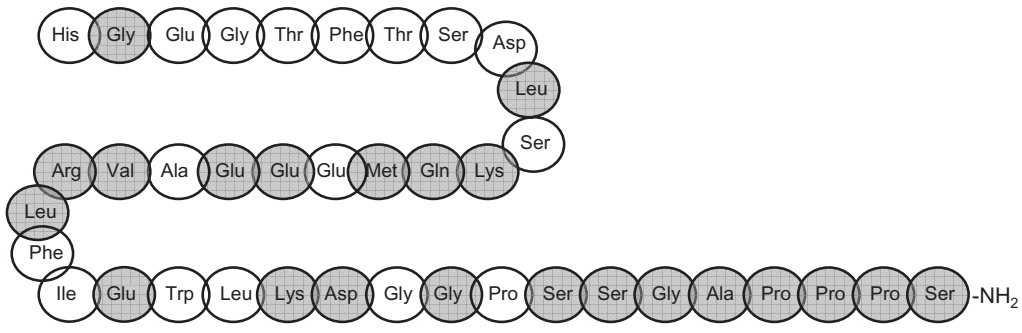

Figure I A) The molecular structure of human GLP-I. B) The molecular structure of exenatide (gray colors indicate differences in structure from human GLP-I. C) The molecular structure of liraglutide (gray colors indicate changes in structure from human GLP-I). 
analogue is produced using the recombinant DNA technology in yeast. ${ }^{42}$ It has a similar effect on the GLP-1 receptor as described for exenatide. A high degree of plasma protein binding causes decreased susceptibility to metabolism by DPP-4 and the half-life following $s c$ administration of liraglutide is approximately 13 hours. ${ }^{43}$ This protracted action profile makes liraglutide suitable for once-daily administration. There are no clinically significant differences in liraglutide pharmacokinetics between male and female subjects, subjects of different race, or elderly and younger subjects. ${ }^{44}$

\section{Efficacy}

\section{Exenatide}

The clinical effects of exenatide treatment have been investigated in six published, randomized, controlled trials with a total of 2731 patients. ${ }^{45}$ A summary of the trials is presented in Table 1. Exenatide as add-on therapy to metformin, ${ }^{46} \mathrm{SU}^{47}$ or both ${ }^{48}$ showed statistically significant improvement in glycemic control $\left(\mathrm{HbA}_{1 \mathrm{c}}\right.$ reduction of $1.0 \%$ (baseline $\mathrm{HbA}_{1 \mathrm{c}}: 8.2 \%$ to $8.6 \%$ ) vs a minor increase of about $0.1 \%$ in the placebo groups) and reduction in fasting plasma glucose $(0.5 \mathrm{mM}$ in the exenatide groups vs an increase of about $1 \mathrm{mM}$ in the placebo groups). In all three studies (the Three Amigos) exenatide was given twice daily in two different doses (of 5 and $10 \mu \mathrm{g}$, respectively). The changes in $\mathrm{HbA}_{1 \mathrm{c}}$ for $10 \mu \mathrm{g}$ exenatide are presented in Table 1. Patients receiving exenatide were more likely to achieve an $\mathrm{HbA}_{1 \mathrm{c}}$ less than $7 \%$ compared with patients receiving placebo-with the best results in the high-dose $(10 \mu \mathrm{g})$ exenatide groups ${ }^{49}$.

The effect of exenatide has also been investigated with insulin as active control. In a 26 -week study of patients inadequately controlled on metformin and SU in combination therapy, addition of exenatide induced similar reductions in $\mathrm{HbA}_{1 \mathrm{c}}\left(1.1 \%\right.$ from baseline $\left.\mathrm{HbA}_{1 \mathrm{c}} 8.2 \%\right)$ as addition of insulin glargine. ${ }^{50}$ In a 52-week study comparing twicedaily biphasic insulin aspart and exenatide (both added to existing metformin and SU treatment), exenatide induced similar reductions in $\mathrm{HbA}_{1 \mathrm{c}}$ as insulin aspart, and provided significantly better postprandial glucose control. ${ }^{51}$

On average the weight loss in the three studies comparing exenatide to placebo amounted to $1.6 \mathrm{~kg}$ in the exenatidetreated patients (baseline body weight: 96 to $100 \mathrm{~kg}$ ). ${ }^{46-48}$ Similar results was seen in a trial comparing exenatide with placebo in patients treated with TZDs. ${ }^{52}$ The difference in body weight change was even bigger in the insulin trials. Body weight in the exenatide group decreased $2.3 \mathrm{~kg}$; significantly different from an increase of $1.8 \mathrm{~kg}$ in the insulin glarginetreated group. ${ }^{50}$ In the exenatide vs insulin aspart trial a significant between-group difference of $4.1 \mathrm{~kg}$ weight loss was found (baseline weight $86 \mathrm{~kg}$ (exenatide group) $/ 83 \mathrm{~kg}$ (insulin aspart group). ${ }^{51}$ Table 1 outlines the weight loss for $10 \mu \mathrm{g}$ exenatide groups in the different studies.

The beneficial effects of exenatide seem to last. In an open-label extension of the Three Amigos studies, 3 years' sustained effects were demonstrated for glycemic control and body weight (decrease in $\mathrm{HbA}_{1 \mathrm{c}}$ of $1 \%$ and body weight of $5.3 \mathrm{~kg}) .{ }^{53} \mathrm{An}$ important limitation of this study, in addition to its open-label design, was a high drop out rate of patients (due to adverse events, insufficient glycemic control, patient/investigator decision, and protocol violation), only 217 out of 517 randomized subjects completing the 3 -year study period.

Only few studies have investigated the effect of exenatide on cardiovascular risk profile. The open-label studies with a 3-year follow-up found minor, but significant improvements in triglycerides ( $12 \%$ decrease compared to baseline), total cholesterol (5\% decrease), low density lipoproteins (6\% decrease) and high density lipoprotein (24\% increase) in favor of a reduced cardiovascular risk. ${ }^{54} \mathrm{~A}$ review looking at exenatide vs placebo or insulin on blood pressure measurements in pooled data from 6 exenatide trials, found that 6 months of exenatide treatment was associated with a significantly greater reduction in systolic blood pressure compared with placebo (difference of $-2.8 \mathrm{mmHg}$ ) or insulin (difference of $-3.7 \mathrm{mmHg}$ ). ${ }^{55}$ Further studies are needed to elucidate the exact mechanisms behind the beneficial effects of exenatide on the cardiovascular risk profile.

\section{Liraglutide}

The clinical effects of liraglutide treatment have been investigated in the LEAD (Liraglutide Effect and Action in Diabetes) series of phase III studies including more than 4000 patients with type 2 diabetes. A summary of the trials is presented in Table 2 with changes in $\mathrm{HbA}_{1 \mathrm{c}}$ of $1.8 \mathrm{mg}$ liraglutide. In average liraglutide reduced $\mathrm{HbA}_{1 \mathrm{c}}$ by $1.2 \%$ from a baseline of $8.2 \%$ to $8.5 \%$. Liraglutide in monotherapy (52 weeks of treatment) compared with the SU glimepiride was evaluated in the LEAD 3 study ${ }^{56}$ using two different doses of liraglutide (1.2 and $1.8 \mathrm{mg}$, respectively). The proportions of participants reaching the target $\mathrm{HbA}_{1 \mathrm{c}}$ of $7.0 \%$ or less were $43 \%, 51 \%$ and $28 \%$ in the $1.2 \mathrm{mg}$ liraglutide, $1.8 \mathrm{mg}$ liraglutide and glimepiride groups, respectively. An open-label one-year extension of the LEAD 3 study showed a sustained beneficial effect of liraglutide compared to glimepiride on $\mathrm{HbA}_{1 \mathrm{c}}{ }^{57}$ Improved glycemic control has also been reported when liraglutide is given in combination with oral antidiabetes therapy. In the LEAD $2^{58}$ different doses of liraglutide 


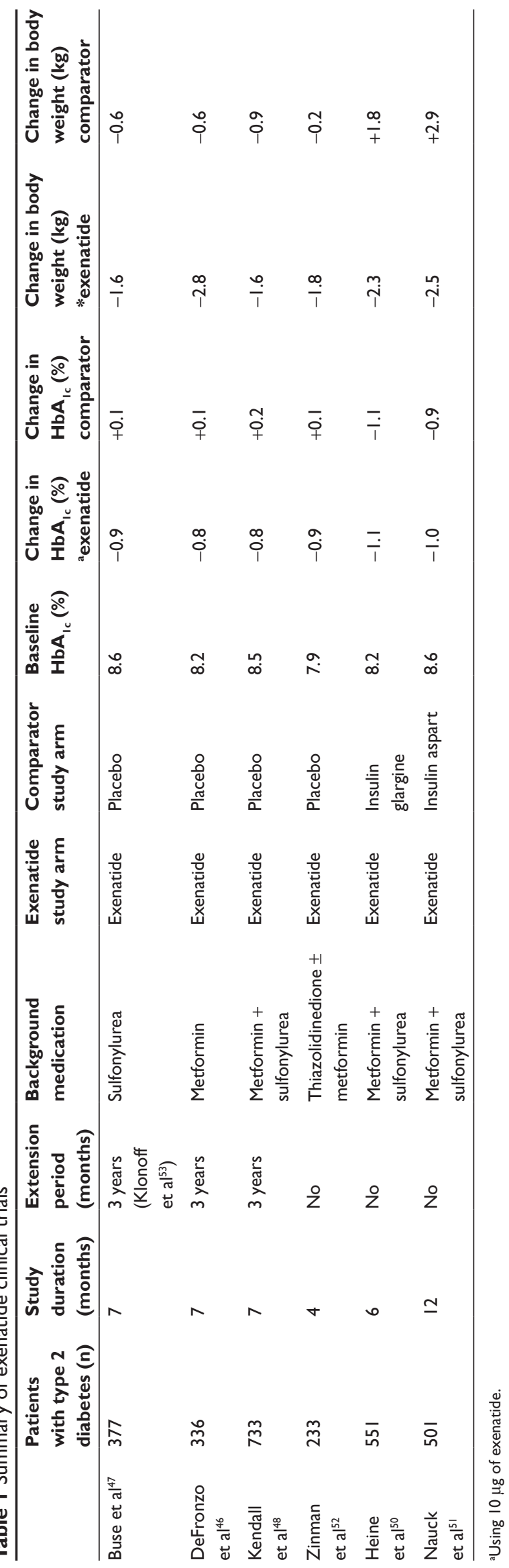

(0.6, 1.2 and $1.8 \mathrm{mg})$, glimepiride and placebo added to existing metformin treatment were evaluated, and in the LEAD 1 study, ${ }^{59}$ liraglutide was added to glimepiride treatment and compared with rosiglitazone and placebo. In the LEAD 4 study $^{60}$ liraglutide was added to metformin in combination with rosiglitazone. Liraglutide $(1.8 \mathrm{mg}$ ) added to metformin in combination with glimepiride was compared to the active comparator insulin glargine (LEAD 5 study) ${ }^{61} \mathrm{~A}$ direct comparison between liraglutide (1.8 mg once daily) and exenatide (10 $\mu \mathrm{g}$ twice daily) was reported from the open-labeled LEAD 6 study. ${ }^{62}$ Mean $\mathrm{HbA}_{1 \mathrm{c}}$ reduction was significantly greater with liraglutide treatment than with exenatide ( $1.1 \%$ vs $0.8 \%)$. Significant differences were also seen between the two agents with regard to fasting plasma glucose $(1.6 \mathrm{mM}$ reduction [liraglutide] vs $0.6 \mathrm{mM}$ reduction [exenatide]). Liraglutide also reduced postprandial glucose across the LEAD trials. As for exenatide, liraglutide has a significant effect on body weight as shown by the data for $1.8 \mathrm{mg}$ liraglutide in Table 2 . Liraglutide reduced mean body weight or was weight neutral as monotherapy ${ }^{56}$ and in combination with one ${ }^{58,59}$ or two $\mathrm{o}^{60-62}$ oral antidiabetes agents compared to placebo or active comparators. The LEAD $6^{62}$ study examined the lipid profile on exenatide and liraglutide. Significant greater reductions in triglycerides $(-0.4 \mathrm{vs}-0.2 \mathrm{mM})$ and free fatty acids $(-0.17 \mathrm{vs}-0.10 \mathrm{mM})$ in the liraglutide group were observed. Both compounds caused a significant decrease in blood pressure (systolic blood pressure $-2.2 \mathrm{mmHg}$ and diastolic pressure $-1.5 \mathrm{mmHg}$ ) with no significant differences between the two compounds.

\section{Safety and tolerability}

The major side-effects of all compounds are mild to moderate and transient nausea and vomiting. These side effects are dose dependent and decline over time. ${ }^{49}$ Other frequently reported side effects encompass headache and upper respiratory infection. ${ }^{41,63}$ The incidence of treatment-associated hypoglycemia is reported to be $\operatorname{low}^{41,63}$ - apparently due to the glucose-dependent insulinotropic and glucagonostatic effects of GLP-1. However, in combination with SU the incidence increases, and is dependent on the dose of SU. In most exenatide trials minor hypoglycemic episodes are defined as plasma glucose $<3.3 \mathrm{mM}$; in the LEAD studies it is defined as plasma glucose $<3.1 \mathrm{mM}$. In studies using exenatide combined with $\mathrm{SU}$ a risk of minor hypoglycemic episodes is reported to be between $15 \%$ and $36 \%{ }^{49}$ In studies combining liraglutide with SU the risk is reported to be $8 \%$ to $25 \%{ }^{64}$ In the exenatide/insulin glargine study $1.5 \%$ of patients experienced severe hypoglycemia. ${ }^{50}$ There was no difference between groups and the incidence was similar in 


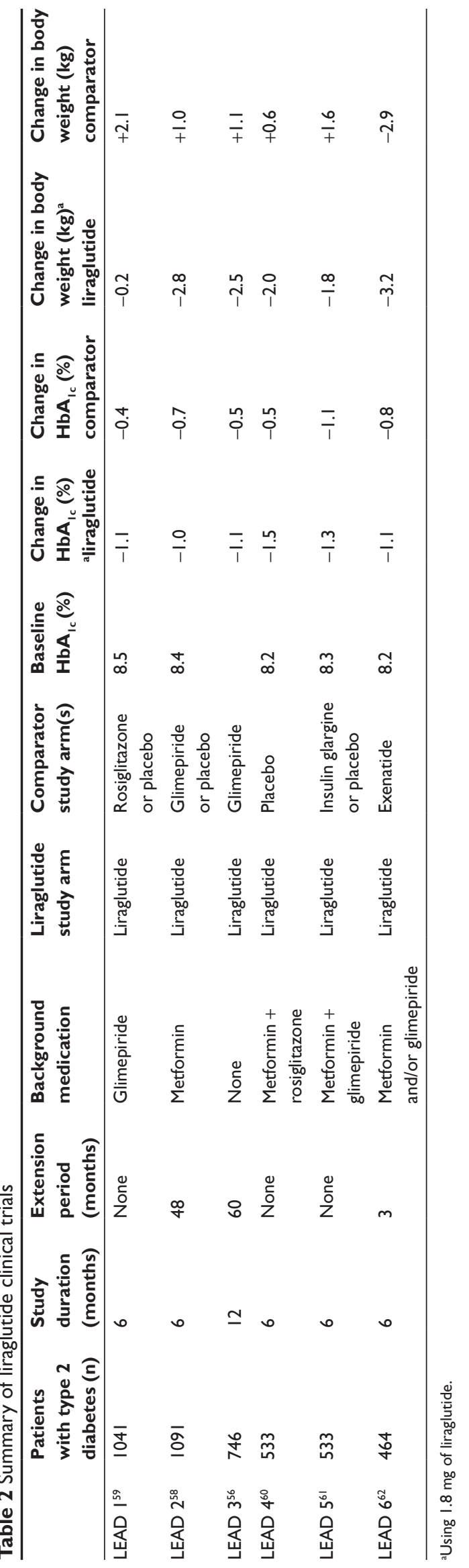

the two groups. Only one severe hypoglycemic episode was reported with liraglutide and glimipiride. ${ }^{58}$

Approximately $40 \%$ of exenatide-treated patients in long-term, placebo-controlled studies developed antibodies against exenatide during the initial 30 weeks of treatment. ${ }^{49}$ Among liraglutide-treated patients up to approximately $8 \%$ exhibit antibodies. ${ }^{56,58-61}$ The exact impact of antibodies in the longer term needs to be established. Neither exenatide nor liraglutide is recommended during pregnancy or lactation due to lack of sufficient data. Exenatide should not be used in patients with kidney failure since it is cleared primarily in the kidneys by glomerular filtration ${ }^{41}$ and reports of acute kidney failure have been filed. No data indicate inhibition or induction of cytochrome P450 drug metabolizing enzymes. Since 2005 the US Food and Drug Administration (FDA) has received 170 reports on pancreatitis in exenatide-treated patients, and recently the FDA received reports of acute pancreatitis, some of which were severe cases of hemorrhagic or necrotizing pancreatitis in patients taking exenatide. In the LEAD studies a total of 9 reports of pancreatitis were observed, with reports of pancreatitis in both in liraglutide-, placebo- and active comparator-treated patients. At this point it is not clear whether a causal relationship between pancreatitis and exenatide/liraglutide exists or the cases are incidental. However, it is recommended to discontinue incretin mimetic treatment if pancreatitis is suspected. ${ }^{65}$ In carcinogenicity studies with liraglutide, C-cell tumors were observed in thyroid tissue of mice and rats. It has been suggested that the findings in rodents are caused by a non-genotoxic, specific GLP-1 receptor-mediated mechanism to which rodents are particularly sensitive. The relevance for humans is likely to be clinical insignificant, but additional studies are needed to clarify the potential mechanisms behind C-cell tumor development in GLP-1 analogue-treated patients and their possible clinical implications. ${ }^{63}$

\section{Patients}

Both products are parenteral solutions intended for sc injection. They can be administered in the subcutis of the abdomen, arm or thigh. To improve gastrointestinal tolerability, exenatide therapy should be initiated at $5 \mu \mathrm{g}$ per dose administered twice daily for at least a month. The dose of exenatide can then be increased to $10 \mu \mathrm{g}$ twice daily. ${ }^{41}$ Liraglutide should be initiated in a dose of $0.6 \mathrm{mg}$ daily. After at least 1 week, the dose should be increased to $1.2 \mathrm{mg}$. The dose can be increased to $1.8 \mathrm{mg}$ to further improve glycemic control. Daily doses higher than $1.8 \mathrm{mg}$ are not recommended because of side effects. Patient satisfaction 
using exenatide has been evaluated in a couple of studies. The addition of exenatide to metformin and SU resulted in significant improvements in treatment satisfaction and patients' health-related quality of life from baseline to 26 weeks. ${ }^{66}$ The improvement was similar for patients treated with insulin glargine.

Liraglutide has been on the market for only a short time and few reports about compliance and satisfaction exist. In the LEAD 6 study, ${ }^{62} 379$ patients completed a diabetes treatment satisfaction questionnaire at baseline and week 26 , which showed a higher satisfaction among patients on liraglutide than on exenatide.

\section{Conclusion}

Incretin mimetics offer a new and interesting treatment modality in diabetes. Clinical studies have shown beneficial effects on glycemic control, body weight, lipid profile and blood pressure. This could imply substantial benefit on macrovascular outcomes. So far the safety profile of incretin mimetics is promising. The main side-effect is mild to moderate and transient (weeks) nausea. The frequency of hypoglycemia - a well-known side effect of several pre-existing antidiabetes treatment modalities - is low and occurs mainly when incretin mimetics are administered in combination with SU. Incretin mimetics are not yet recommended in combination with insulin. Animal studies indicate that administration of GLP-1 receptor agonists is associated with beta-cell proliferation and beta-cell protection, but these effects have not yet been established in clinical trials. Thus, future mechanistic studies and more long-term clinical studies are required to elucidate these promising outcomes. Treatment with incretin mimetics is also associated with unsolved problems: The reports about acute pancreatitis and rodent $\mathrm{C}$-cell carcinomas have caused concerns about long-term effects, but there are as yet no indications of these effects in humans. These concerns, taken together with the relatively short overall clinical experience, resulted in the label "less validated" treatment in the recent consensus statement for the management of type 2 diabetes from the American Diabetes Association and the European Association for the Study of Diabetes. However, new incretin mimetics are in the pipeline of several pharmaceutical companies. They are all characterized by improved pharmacology and longer half-lives, implying fewer injections. The next couple of years will elucidate whether the incretin mimetics will become well established in the treatment of type 2 diabetes. The data so far are encouraging.

\section{Disclosures}

The authors have no conflict of interests in relation to the present paper.

\section{References}

1. World Health Organization, Geneva. Definition, Diagnosis and Classification of Diabetes Mellitus and its Complications. Report of a WHO Consultation. World Health Organization Department of Noncommunicable Disease Surveillance; 1999.

2. Roglic G, Unwin N, Bennett PH, et al. The burden of mortality attributable to diabetes: realistic estimates for the year 2000. Diabetes Care. 2005;28:2130-2135.

3. Wild S, Roglic G, Green A, Sicree R, King H. Global prevalence of diabetes: estimates for the year 2000 and projections for 2030. Diabetes Care. 2004;27:1047-1053.

4. King H, Aubert RE, Herman WH. Global burden of diabetes, 1995-2025: prevalence, numerical estimates, and projections. Diabetes Care. 1998;21:1414-1431.

5. Intensive blood-glucose control with sulphonylureas or insulin compared with conventional treatment and risk of complications in patients with type 2 diabetes (UKPDS 33). UK Prospective Diabetes Study (UKPDS) Group. Lancet. 1998;352:837-853.

6. Gaede P, Lund-Andersen H, Parving HH, Pedersen O. Effect of a multifactorial intervention on mortality in type 2 diabetes. $N$ Engl J Med. 2008;358:580-591.

7. Patel A, MacMahon S, Chalmers J, et al. Intensive blood glucose control and vascular outcomes in patients with type 2 diabetes. $N$ Engl $J$ Med. 2008;358:2560-2572.

8. Gerstein HC, Miller ME, Byington RP, et al. Effects of intensive glucose lowering in type 2 diabetes. $N$ Engl J Med. 2008;358:2545-2559.

9. Duckworth W, Abraira C, Moritz T, et al. Glucose control and vascular complications in veterans with type 2 diabetes. $N$ Engl J Med. 2009;360:129-139.

10. Nathan DM, Buse JB, Davidson MB, et al. Medical management of hyperglycaemia in type 2 diabetes mellitus: a consensus algorithm for the initiation and adjustment of therapy: a consensus statement from the American Diabetes Association and the European Association for the Study of Diabetes. Diabetologia. 2009;52:17-30.

11. Bolen S, Feldman L, Vassy J, et al. Systematic review: comparative effectiveness and safety of oral medications for type 2 diabetes mellitus. Ann Intern Med. 2007;147:386-399.

12. Maedler K, Carr RD, Bosco D, Zuellig RA, Berney T, Donath MY. Sulfonylurea induced beta-cell apoptosis in cultured human islets. J Clin Endocrinol Metab. 2005;90:501-506.

13. Holst JJ. The physiology of glucagon-like peptide 1. Physiol Rev. 2007;87:1409-1439.

14. Nauck MA, Homberger E, Siegel EG, et al. Incretin effects of increasing glucose loads in man calculated from venous insulin and C-peptide responses. J Clin Endocrinol Metab. 1986;63:492-498.

15. Brown JC, Mutt V, Pederson RA. Further purification of a polypeptide demonstrating enterogastrone activity. J Physiol. 1970;209:57-64.

16. Deacon CF, Johnsen AH, Holst JJ. Degradation of glucagon-like peptide-1 by human plasma in vitro yields an N-terminally truncated peptide that is a major endogenous metabolite in vivo. J Clin Endocrinol Metab. 1995;80:952-957.

17. Vilsboll T, Agerso H, Lauritsen T, et al. The elimination rates of intact GIP as well as its primary metabolite, GIP 3-42, are similar in type 2 diabetic patients and healthy subjects. Regul Pept. 2006;137:168-172.

18. Drucker DJ. The biology of incretin hormones. Cell Metab. 2006;3: 153-165.

19. Orskov C, Holst JJ, Poulsen SS, Kirkegaard P. Pancreatic and intestinal processing of proglucagon in man. Diabetologia. 1987;30:874-881.

20. Orci L, Bordi C, Unger RH, Perrelet A. Glucagon- and glicentinproducing cells. In: Lefebvre PJ, editor. Glucagon. Berlin: Springer Verlag; 1983. P. 57-79. 
21. Goke R, Larsen PJ, Mikkelsen JD, Sheikh SP. Distribution of GLP-1 binding sites in the rat brain: evidence that exendin-4 is a ligand of brain GLP-1 binding sites. Eur J Neurosci. 1995;7:2294-2300.

22. Flint A, Raben A, Astrup A, Holst JJ. Glucagon-like peptide 1 promotes satiety and suppresses energy intake in humans. J Clin Invest. 1998; 101:515-520.

23. Gros R, You X, Baggio LL, et al. Cardiac function in mice lacking the glucagon-like peptide-1 receptor. Endocrinology. 2003;144:2242-2252.

24. Meier JJ, Gethmann A, Gotze O, et al. Glucagon-like peptide 1 abolishes the postprandial rise in triglyceride concentrations and lowers levels of non-esterified fatty acids in humans. Diabetologia. 2006;49:452-458.

25. Carraro-Lacroix LR, Malnic G, Girardi AC. Regulation of $\mathrm{Na}+\mathrm{H}+$ exchanger NHE3 by glucagon-like peptide 1 receptor agonist exendin-4 in renal proximal tubule cells. Am J Physiol Renal Physiol. 2009;297: F1647-F1655.

26. Gault VA, O'Harte FP, Flatt PR. Glucose-dependent insulinotropic polypeptide (GIP): anti-diabetic and anti-obesity potential? Neuropeptides. 2003;37:253-263.

27. Tsukiyama K, Yamada Y, Yamada C, et al. Gastric inhibitory polypeptide as an endogenous factor promoting new bone formation after food ingestion. Mol Endocrinol. 2006;20:1644-1651.

28. Knop FK, Vilsboll T, Hojberg PV, et al. Reduced incretin effect in type 2 diabetes: cause or consequence of the diabetic state? Diabetes. 2007;56:1951-1959.

29. Nauck M, Stockmann F, Ebert R, Creutzfeldt W. Reduced incretin effect in type 2 (non-insulin-dependent) diabetes. Diabetologia. 1986;29:46-52

30. Bagger JO, Knop FK, Lund A, Vestergaard H, Holst JJ, Vilsboll T. Impaired Regulation of the Incretin Effect in Patients with Type 2 Diabetes Mellitus. Diabetes. 2010;58 Suppl 1:A369.

31. Vilsboll T, Krarup T, Deacon CF, Madsbad S, Holst JJ. Reduced postprandial concentrations of intact biologically active glucagon-like peptide 1 in type 2 diabetic patients. Diabetes. 2001;50:609-613.

32. Kjems LL, Holst JJ, Volund A, Madsbad S. The influence of GLP-1 on glucose-stimulated insulin secretion: effects on beta-cell sensitivity in type 2 and nondiabetic subjects. Diabetes. 2003;52:380-386.

33. Nauck MA, Heimesaat MM, Orskov C, Holst JJ, Ebert R, Creutzfeldt W. Preserved incretin activity of glucagon-like peptide 1 [7-36 amide] but not of synthetic human gastric inhibitory polypeptide in patients with type-2 diabetes mellitus. J Clin Invest. 1993;91:301-307.

34. Nauck MA, Kleine N, Orskov C, Holst JJ, Willms B, Creutzfeldt W. Normalization of fasting hyperglycaemia by exogenous glucagon-like peptide 1 (7-36 amide) in type 2 (non-insulin-dependent) diabetic patients. Diabetologia. 1993;36:741-744.

35. Eng J, Kleinman WA, Singh L, Singh G, Raufman JP. Isolation and characterization of exendin-4, an exendin-3 analogue, from Heloderma suspectum venom. Further evidence for an exendin receptor on dispersed acini from guinea pig pancreas. $J$ Biol Chem. 1992;267:7402-7405.

36. Thorens B, Porret A, Buhler L, Deng SP, Morel P, Widmann C. Cloning and functional expression of the human islet GLP-1 receptor. Demonstration that exendin-4 is an agonist and exendin-(9-39) an antagonist of the receptor. Diabetes. 1993;42:1678-1682.

37. Edwards CM, Stanley SA, Davis R, et al. Exendin-4 reduces fasting and postprandial glucose and decreases energy intake in healthy volunteers. Am J Physiol Endocrinol Metab. 2001;281:E155-E161.

38. Simonsen L, Holst JJ, Deacon CF. Exendin-4, but not glucagon-like peptide-1, is cleared exclusively by glomerular filtration in anaesthetised pigs. Diabetologia. 2006;49:706-712.

39. Malloy J, Capparelli E, Gottschalk M, Guan X, Kothare P, Fineman M. Pharmacology and tolerability of a single dose of exenatide in adolescent patients with type 2 diabetes mellitus being treated with metformin: a randomized, placebo-controlled, single-blind, dose-escalation, crossover study. Clin Ther. 2009;31:806-815.

40. Iwamoto K, Nasu R, Yamamura A, et al. Safety, tolerability, pharmacokinetics, and pharmacodynamics of exenatide once weekly in Japanese patients with type 2 diabetes. Endocr J. 2009;56: 951-962.
41. European medicines Agency. European Public Assessment Report Byetta. EMEA/H/C/698; 2006.

42. Knudsen LB, Nielsen PF, Huusfeldt PO, et al. Potent derivatives of glucagon-like peptide-1 with pharmacokinetic properties suitable for once daily administration. $J$ Med Chem. 2000;43:1664-1669.

43. Elbrond B, Jakobsen G, Larsen S, et al. Pharmacokinetics, pharmacodynamics, safety, and tolerability of a single-dose of NN2211, a long-acting glucagon-like peptide 1 derivative, in healthy male subjects. Diabetes Care. 2002;25:1398-1404.

44. Damholt B, Golor G, Wierich W, Pedersen P, Ekblom M, Zdravkovic M. An open-label, parallel group study investigating the effects of age and gender on the pharmacokinetics of the once-daily glucagonlike peptide-1 analogue liraglutide. J Clin Pharmacol. 2006;46: 635-641.

45. Bosi E, Lucotti P, Setola E, Monti L, Piatti PM. Incretin-based therapies in type 2 diabetes: A review of clinical results. Diabetes Res Clin Pract. 2008;82 Supp1 2:S102-S107.

46. DeFronzo RA, Ratner RE, Han J, Kim DD, Fineman MS, Baron AD. Effects of exenatide (exendin-4) on glycemic control and weight over 30 weeks in metformin-treated patients with type 2 diabetes. Diabetes Care. 2005;28:1092-1100.

47. Buse JB, Henry RR, Han J, Kim DD, Fineman MS, Baron AD. Effects of exenatide (exendin-4) on glycemic control over 30 weeks in sulfonylurea-treated patients with type 2 diabetes. Diabetes Care. 2004;27:2628-2635.

48. Kendall DM, Riddle MC, Rosenstock J, et al. Effects of exenatide (exendin-4) on glycemic control over 30 weeks in patients with type 2 diabetes treated with metformin and a sulfonylurea. Diabetes Care. 2005;28:1083-1091.

49. Amori RE, Lau J, Pittas AG. Efficacy and safety of incretin therapy in type 2 diabetes: systematic review and meta-analysis. JAMA. 2007;298:194-206.

50. Heine RJ, Van Gaal LF, Johns D, Mihm MJ, Widel MH, Brodows RG. Exenatide versus insulin glargine in patients with suboptimally controlled type 2 diabetes: a randomized trial. Ann Intern Med. 2005;143: $559-569$.

51. Nauck MA, Duran S, Kim D, et al. A comparison of twice-daily exenatide and biphasic insulin aspart in patients with type 2 diabetes who were suboptimally controlled with sulfonylurea and metformin: a non-inferiority study. Diabetologia. 2007;50:259-267.

52. Zinman B, Hoogwerf BJ, Duran GS, et al. The effect of adding exenatide to a thiazolidinedione in suboptimally controlled type 2 diabetes: a randomized trial. Ann Intern Med. 2007;146:477-485.

53. Klonoff DC, Buse JB, Nielsen LL, et al. Exenatide effects on diabetes, obesity, cardiovascular risk factors and hepatic biomarkers in patients with type 2 diabetes treated for at least 3 years. Curr Med Res Opin. 2008;24:275-286.

54. Klonoff DC, Buse JB, Nielsen LL, et al. Exenatide effects on diabetes, obesity, cardiovascular risk factors and hepatic biomarkers in patients with type 2 diabetes treated for at least 3 years. Curr Med Res Opin. 2008;24:275-286.

55. Okerson T, Yan P, Stonehouse A, Brodows R. Effects of exenatide on systolic blood pressure in subjects with type 2 diabetes. Am J Hypertens. 2010;23:334-339.

56. Garber A, Henry R, Ratner R, et al. Liraglutide versus glimepiride monotherapy for type 2 diabetes (LEAD-3 Mono): a randomised, 52-week, phase III, double-blind, parallel-treatment trial. Lancet. 2009;373:473-481.

57. Garber A, Henry R, Ratner R, Hale PM, Chang CT, Bode B. Liraglutide, a human GLP-1 analogue, maintains greater reductions in $\mathrm{HbA}_{1 c}$, FPG and weight than glimepiride over 2 years in patients with type 2 diabetes: LEAD-3 extension study. Diabetologia. 2010;52 Suppl 1:S287.

58. Nauck MA, Frid A, Hermansen K, et al; for the LEAD-2 Metformin Study Group. Efficacy and safety comparison of liraglutide, glimepiride and placebo, all in combination with metformin in type 2 diabetes mellitus. Diabetes Care. 2009;32:84-90. 
59. Marre M, Shaw J, Brandle M, et al. Liraglutide, a once-daily human GLP-1 analogue, added to a sulphonylurea over 26 weeks produces greater improvements in glycaemic and weight control compared with adding rosiglitazone or placebo in subjects with Type 2 diabetes (LEAD-1 SU). Diabet Med. 2009;26:268-278.

60. Zinman B, Gerich J, Buse JB, et al. Efficacy and safety of the human glucagon-like peptide-1 analog liraglutide in combination with metformin and thiazolidinedione in patients with type 2 diabetes (LEAD-4 Met + TZD). Diabetes Care. 2009;32:1224-1230.

61. Russell-Jones D, Vaag A, Schmitz O, et al. Liraglutide vs insulin glargine and placebo in combination with metformin and sulfonylurea therapy in type 2 diabetes mellitus (LEAD-5 met $+\mathrm{SU}$ ): a randomised controlled trial. Diabetologia. 2009;52:2046-2055.

62. Buse JB, Rosenstock J, Sesti G, et al. Liraglutide once a day versus exenatide twice a day for type 2 diabetes: a 26-week randomised, parallel-group, multinational, open-label trial (LEAD-6). Lancet. 2009;374:39-47.
63. European medicines Agency. European Public Assessment Report Victoza. EMEA/H/C/1026; 2009.

64. Blonde L, Russell-Jones D. The safety and efficacy of liraglutide with or without oral antidiabetic drug therapy in type 2 diabetes: an overview of the LEAD 1-5 studies. Diabetes Obes Metab. 2009;11 Suppl 3: 26-34.

65. US Food and Drug Administration. Information for Healthcare Professionals Exenatide (marketed as Byetta). [press release] 2009. http://www.fda.gov/Drugs/DrugSafety/PostmarketDrugSafetyInformationforPatientsandProviders/ucm124713.htm.

66. Cvetkovic RS, Plosker GL. Exenatide: a review of its use in patients with type 2 diabetes mellitus (as an adjunct to metformin and/or a sulfonylurea). Drugs. 2007;67:935-954.

\section{Publish your work in this journal}

Diabetes, Metabolic Syndrome and Obesity: Targets and Therapy is an international, peer-reviewed open-access journal committed to the rapid publication of the latest laboratory and clinical findings in the fields of diabetes, metabolic syndrome and obesity research. Original research, review, case reports, hypothesis formation, expert opinion and commentaries are all considered for publication. The manuscript management system is completely online and includes a very quick and fair peer-review system, which is all easy to use. Visit http://www.dovepress.com/testimonials.php to read real quotes from published authors.

Submit your manuscript here: http://www.dovepress.com/diabetes-metabolic-syndrome-and-obesity-targets-and-therapy-journal 